\title{
Editorial
}

Dermatology 2006;212:321-323

DOI: $10.1159 / 000092281$

\section{Biological Agents and Psoriatic Epidermis: What Are We Ultimately Targeting?}

\author{
M. Heenen T. Simonart \\ Department of Dermatology, Erasme University Hospital, Brussels, Belgium
}

\section{Key Words}

Biological agents $\cdot$ Hyperproliferation $\cdot$ Psoriasis

The typical psoriatic histology results from a markedly increased germinative compartment [1-3]. However, the mechanisms that drive keratinocyte hyperproliferation in psoriasis remain speculative. More particularly, it is controversial as to whether psoriasis results from a primary abnormality in epidermal keratinocytes with secondary inflammation (outside-in hypothesis) or from deregulation of the immune system leading to a psoriatic phenotype (inside-out hypothesis) [4]. The possible role of misguided T-cell responses in psoriasis emerged more than 25 years ago when cyclosporin A, an immunosuppressive agent targeting $\mathrm{T}$ cells, was found to improve psoriatic lesions [5]. This hypothesis was supported by the observation that psoriasis developed in a bone marrow recipient from a donor with psoriasis and, vice versa, psoriasis may not recur after bone marrow transplantation from healthy donors [6, 7]. Further research showed that $\mathrm{T}$ cells from patients with psoriasis could transfer disease in animal models [8]. In addition, there are increased levels of activated T lymphocytes in psoriatic skin plaques and blood of patients [9]. This evolving under- standing of the role of $\mathrm{T}$ cells in psoriasis has provided a sound platform for the rational design of new biological agents and biological-immune-response modifiers that target specific steps in psoriasis-associated inflammation, i.e. inhibition of T-cell activation, depletion of pathogenic T cells, inhibition of leukocyte recruitment, inhibition of inflammatory cytokines and immune deviation from Th1 to Th2 cytokines. Accumulative clinical data support the use of some of these agents as efficient molecules for the control of psoriasis flares or for the maintenance of disease clearing. Three of these agents - etanercept, which is a soluble tumor necrosis factor (TNF), alefacept (LFA3TIP) and efalizumab (anti-CD11a), both of which act via inhibition of T-cell activation - have been licensed for the treatment of moderate to severe chronic plaque psoriasis in the USA as well as in some European countries [10]. Several others (e.g. other TNF antagonists such as infliximab and adalimumab) are in the final phase of clinical development [10]. These drugs are considered to be more targeted and to have fewer side effects than conventional antipsoriasis systemic medications [10]. However, a diversity of side effects, commonly involving the skin, is being reported with the increasing use of these drugs [11]. In addition, their role in the context of existing standard therapies, particularly with respect to efficacy and long-term toxicity, is uncertain. More particu-

\section{KARGER}

Fax +4161306 1234

E-Mail karger@karger.ch

www.karger.com
C 2006 S. Karger AG, Basel

$1018-8665 / 06 / 2124-0321 \$ 23.50 / 0$

Accessible online at:

www.karger.com/drm
Dr. T. Simonart

Department of Dermatology, Erasme University Hospital

808 , route de Lennik

BE-1070 Brussels (Belgium)

Tel. +32 255546 12, Fax +32 255549 69, E-Mail tsimonar@ulb.ac.be 
larly, most of these therapies targeting $\mathrm{T}$ cells are not disease remitting but disease suppressing, as psoriasis begins to recur or flares shortly after course completion [10]. Indeed, among the most promising biological agents (alefacept, efalizumab, etanercept and infliximab), only alefacept has been shown to produce long remissions and has been categorised as disease remitting [10]. However, it is not as effective as cyclosporin A or methotrexate [10].

While there is no doubt that the primary target of these molecules are $\mathrm{T}$ cells, it remains unclear how these agents lead to the regression of epidermal hyperplasia which remains the hallmark of the psoriatic phenotype. Several pathways could be conceptually considered. (1) As supernatants from subpopulations of lesional psoriatic $\mathrm{T}$ lymphocytes are capable of enhancing keratinocyte proliferation in vitro $[12,13]$, it is commonly assumed that increased epidermal proliferation in psoriasis results from a decrease in epidermal cell cycle time and, inversely, that antipsoriasis agents might act through a reduction of cell cycle time of the germinative cells. However, accumulative evidence shows that the psoriatic abnormality is not due to a reduction in the cell cycle time [14, 15]. Accordingly, mathematical simulations show that a decrease in germinative cell cycle time cannot alone reduce the increased size of the germinative compartment that characterises psoriatic lesions [1]. Furthermore, the exact mechanisms by which cytokines secreted by activated $\mathrm{T}$ cells affect keratinocyte proliferation needs further clarification. TNF- $\alpha$ and IFN- $\gamma$, two of the major cytokines involved in the psoriatic tissue reaction, are inhibitors rather than stimulators of human keratinocyte growth [16-18]. However, they can induce expression of proproliferative genes downstream [19]. (2) Induction of keratinocyte apoptosis appears to be a more likely mechanism involved in the reduction of epidermal hyperplasia. Keratinocytes within psoriatic plaques have a capacity to resist induction of apoptosis and have abundant amounts of the cell survival protein $\mathrm{Bcl}-\mathrm{xL}$ [20,21]. This resistance to apoptosis may be due to a modulatory effect of some cytokines, such as IFN- $\gamma$ [13]. Supporting this hypothesis, various therapeutic agents active in psoriasis (anthralin, methotrexate, PUVA therapy ...) have been shown to lead to apoptosis of germinative cells [22, 23]. However, there are so far no data on the eventual induction of keratinocyte apoptosis by biologicals in psoriasis. (3) A last possibility is that antipsoriatic therapies ultimately act at the level of transit-amplifying cells. A decrease in the proliferative potential of the transit-amplifying compartment would have a dramatic effect on the number of keratinocytes: one less round of cell division would divide by two the number of cells in the germinative compartment. However, even at this point several possibilities exist: antipsoriatic agents could drive basal transit-amplifying cells to the $\mathrm{G}_{0}$ phase of the cell cycle by interfering with a vicious (autocrine) loop, inhibit proliferation of late transit-amplifying cells in the suprabasal layer or promote normal differentiation of the suprabasal compartment.

There is so far no evidence that biologicals act on the primum movens of psoriasis. Rather, most of the new developments might only target single steps in a complex cascade of humoral and cellular inflammatory immunomechanisms. More particularly, it remains controversial whether psoriasis is triggered and propagated by the $\mathrm{T}$ cell or within the epidermis with immunological consequences [24]. Recently elaborated mouse models based on abrogation of JunB/activator protein 1 or on activation of mitogen-activated protein kinase or of cell-signaling molecules such as Stat 3 in keratinocytes produce conditions very similar to human psoriasis, indicating that skin lesions may develop independently of immune cells and suggesting that the outside-in and inside-out hypotheses are not mutually exclusive [4, 25-27].

In summary, biological agents have emerged as novel therapeutic options for the control of moderate-to-severe psoriasis. Given the widespread patient dissatisfaction with standard treatments [28], the demand is likely to be high. However, there is so far no evidence that these agents target psoriasis more specifically than agents acting directly on keratinocytes. Their use is also hindered by their high costs, by their potential adverse events, by their varying efficacies and by the relapse of the disease upon discontinuation. Because epidermal keratinocytes and $\mathrm{T}$ cells may pair up to generate psoriasis, therapies focusing both on the epidermis and immune cells may be useful. In this perspective, a combination of biologicals with therapies directly targeting epidermal alterations seems rational and may allow for improved therapeutic efficacy with fewer side effects. 


\section{References}

1 Heenen M, Galand P, de Maertelaer V, Heenen M: Psoriasis: hyperproliferation cannot induce characteristic epidermal morphology. Cell Tissue Kinet 1987;20:561-570.

2 Heenen M: On the morphogenesis of a psoriatic lesion. J Invest Dermatol 1998;111:174.

3 Iizuka H, Takahashi H, Ishida-Yamamoto A: Psoriatic architecture constructed by epidermal remodeling. Dermatol Sci 2004;35:9399.

4 Zenz R, Eferl R, Kenner L, Florin L, Hummerich L, Mehic D, Scheuch H, Angel P, Tschachler E, Wagner EF: Psoriasis-like skin disease and arthritis caused by inducible epidermal deletion of Jun proteins. Nature 2005; 437:369-375.

5 Mueller W, Hermann B: Cyclosporine A for psoriasis. N Engl J Med 1979;301:555.

6 Eedy DJ, Burrows D, Bridges JM, Jones FG: Clearance of severe psoriasis after allogenic bone marrow transplantation. BMJ 1990;300: 908.

7 Gardembas-Pain M, Ifrah N, Foussard C, Boasson M, Saint Andre JP, Verret JL: Psoriasis after allogeneic bone marrow transplantation. Arch Dermatol 1990;126:1523.

8 Wrone-Smith T, Nickoloff BJ: Dermal injection of immunocytes induces psoriasis. J Clin Invest 1996;98:1878-1887.

9 Gottlieb AB: Immunologic mechanisms in psoriasis. J Invest Dermatol 1990;95:18S19S.

10 Kipnis CD, Myers WA, Opeola M, Gottlieb AB: Biologic treatments for psoriasis. J Am Acad Dermatol 2005;52:671-682.

11 Thielen AM, Kuenzli S, Saurat JH: Cutaneous adverse events of biological therapy for psoriasis: review of the literature. Dermatology 2005; 211:209-217.

12 Prinz JC, Gross B, Vollmer S, Trommler P, Strobel I, Meurer M, Plewig G: T cell clones from psoriasis skin lesions can promote keratinocyte proliferation in vitro via secreted products. Eur J Immunol 1994;24:593-598.
13 Nickoloff BJ: The immunologic and genetic basis of psoriasis. Arch Dermatol 1999;135: 1104-1110.

14 Castelijns FA, Gerritsen MJ, van Erp PE, van de Kerkhof PC: Cell-kinetic evidence for increased recruitment of cycling epidermal cells in psoriasis: the ratio of histone and $\mathrm{Ki}-67$ antigen expression is constant. Dermatology 2000;201:105-110.

15 Franssen ME, Zeeuwen PL, Vierwinden G, van de Kerkhof PC, Schalkwijk J, van Erp PE: Phenotypical and functional differences in germinative subpopulations derived from normal and psoriatic epidermis. J Invest Dermatol 2005; 124:373-383.

16 Fransson J: Tumour necrosis factor-alpha does not influence proliferation and differentiation of healthy and psoriatic keratinocytes in a skinequivalent model. Acta Derm Venereol 2000; 80:416-420.

17 Jackson M, Howie SE, Weller R, Sabin E, Hunter JA, McKenzie RC: Psoriatic keratinocytes show reduced IRF-1 and STAT-1alpha activation in response to gamma-IFN. FASEB J 1999; 13:495-502.

18 Hattori N, Komine M, Yano S, Kaneko T, Hanakawa Y, Hashimoto K, Tamaki K: Interferon-gamma, a strong suppressor of cell proliferation, induces upregulation of keratin K6, one of the inflammatory- and proliferation-associated keratins. J Invest Dermatol 2002;119: 403-410.

19 Banno T, Gazel A, Blumenberg M: Effects of tumor necrosis factor-alpha (TNF alpha) in epidermal keratinocytes revealed using global transcriptional profiling. J Biol Chem 2004; 279:32633-32642.

20 Wrone-Smith T, Johnson T, Nelson B, Boise LH, Thompson CB, Nunez G, Nickoloff BJ: Discordant expression of $\mathrm{Bcl}-\mathrm{x}$ and $\mathrm{Bcl}-2$ by keratinocytes in vitro and psoriatic keratinocytes in vivo. Am J Pathol 1995; 146:10791088 .
21 Laporte M, Galand P, Fokan D, de Graef C, Heenen M: Apoptosis in established and healing psoriasis. Dermatology 2000;200:314316 .

22 McGill A, Frank A, Emmett N, Turnbull DM, Birch-Machin MA, Reynolds NJ: The antipsoriatic drug anthralin accumulates in keratinocyte mitochondria, dissipates mitochondrial membrane potential, and induces apoptosis through a pathway dependent on respiratory competent mitochondria. FASEB J 2005;19: 1012-1014.

23 Heenen M, Laporte M, Noel JC, de Graef C: Methotrexate induces apoptotic cell death in human keratinocytes. Arch Dermatol Res 1998;290:240-245.

24 Pittelkow MR: Psoriasis: more than skin deep. Nat Med 2005;11:17-18.

25 Hobbs RM, Silva-Vargas V, Groves R, Watt FM: Expression of activated MEK1 in differentiating epidermal cells is sufficient to generate hyperproliferative and inflammatory skin lesions. J Invest Dermatol 2004; 123:503515 .

26 Voskas D, Jones N, Van Slyke P, Sturk C, Chang W, Haninec A, Babichev YO, Tran J, Master Z, Chen S, Ward N, Cruz M, Jones J, Kerbel RS, Jothy S, Dagnino L, Arbiser J, Klement G, Dumont DJ: A cyclosporine-sensitive psoriasis-like disease produced in Tie2 transgenic mice. Am J Pathol 2005; 166:843855 .

27 Sano S, Chan KS, Carbajal S, Clifford J, Peavey M, Kiguchi K, Itami S, Nickoloff BJ, DiGiovanni J: Stat 3 links activated keratinocytes and immunocytes required for development of psoriasis in a novel transgenic mouse model. Nat Med 2005; 11:43-49.

28 Stern RS, Nijsten T, Feldman SR, Margolis DJ, Rolstad T: Psoriasis is common, carries a substantial burden even when not extensive, and is associated with widespread treatment dissatisfaction. J Invest Dermatol Symp Proc 2004;9:136-139. 